Provided for non-commercial research and education use. Not for reproduction, distribution or commercial use.

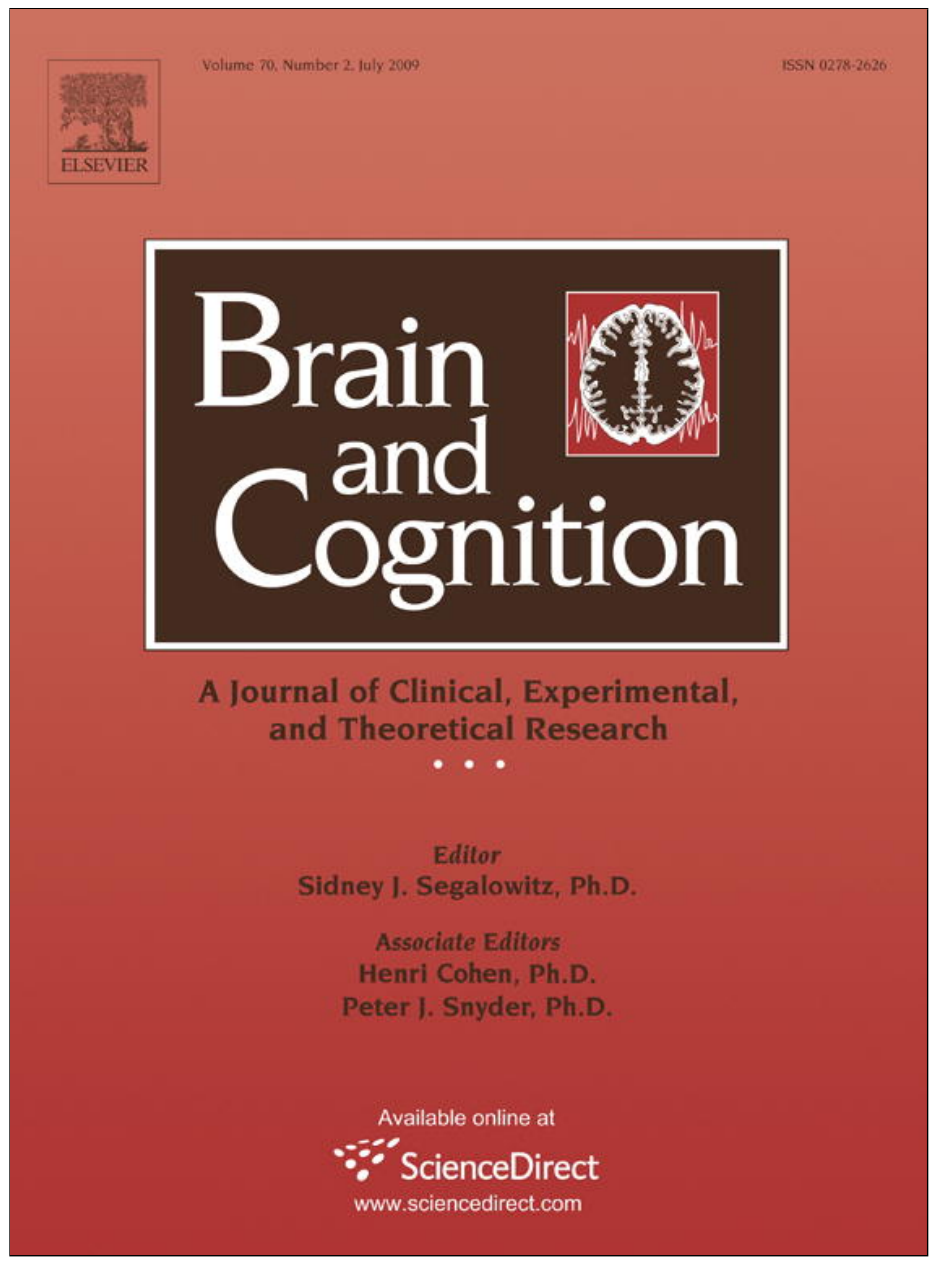

This article appeared in a journal published by Elsevier. The attached copy is furnished to the author for internal non-commercial research and education use, including for instruction at the authors institution and sharing with colleagues.

Other uses, including reproduction and distribution, or selling or licensing copies, or posting to personal, institutional or third party websites are prohibited.

In most cases authors are permitted to post their version of the article (e.g. in Word or Tex form) to their personal website or institutional repository. Authors requiring further information regarding Elsevier's archiving and manuscript policies are encouraged to visit:

http://www.elsevier.com/copyright 


\title{
Face-name repetition priming in semantic dementia: A case report
}

\author{
Marco Calabria ${ }^{a}$, Carlo Miniussi ${ }^{\mathrm{a}, \mathrm{b}}$, Patrizia S. Bisiacchi ${ }^{\mathrm{c}}$, Orazio Zanetti ${ }^{\mathrm{a}}$, Maria Cotelli ${ }^{\mathrm{a}, *}$ \\ a IRCCS San Giovanni di Dio Fatebenefratelli, Via Piastroni, 425125 Brescia, Italy \\ ${ }^{\mathrm{b}}$ Department of Biomedical Sciences and Biotechnologies, Physiology Section, National Institute of Neuroscience, University of Brescia, Italy \\ ${ }^{\mathrm{c}}$ Department of General Psychology, University of Padua, Padua, Italy
}

\section{A R T I C L E I N F O}

\section{Article history:}

Accepted 5 February 2009

Available online 13 March 2009

\section{Keywords:}

Semantic dementia

Proper naming

Face processing

Repetition priming

\begin{abstract}
A B S T R A C T
Repetition priming (RP) has been employed as a measure of implicit processing in patients suffering from a breakdown of semantic memory, as in the case of semantic dementia (SD), a subtype of frontotemporal lobar degeneration (FTLD). Here, we investigated face-name representation in a case of SD using a paradigm of within- and cross-domain repetition priming. Compared to ten healthy participants, SD patient did not show any facilitation when a famous name was primed by its own face (cross-domain) or when the prime was the same proper name (within-domain). Results are discussed within the hypothesis of a degradation of face and name representation, one of the most consistent accounts explaining semantic deficits in SD.
\end{abstract}

(c) 2009 Elsevier Inc. All rights reserved.

\section{Introduction}

Famous face recognition and proper naming impairments are neuropsychological deficits occurring following a wide range of brain damage types, including stroke, traumatic brain injury and neurodegenerative disease (Bauer, 2003; De Haan, 2000; Semenza, Mondini, Borgo, Pasini, \& Sgaramella, 2003; Semenza, Mondini, \& Zettini, 1995; Werheid \& Clare, 2007). When, in dementia, impairments with regard to famous faces and names occur, these are characterised by an insidious onset and a progressive manifestation. In particular, these deficits are common in patients affected by semantic dementia (SD), a clinical subtype of frontotemporal lobar degeneration (FTLD) (i.e., Snowden, Thompson, \& Neary, 2004). The diagnostic label of FTLD encompasses a number of heterogeneous clinical manifestations, in which different patterns of impairment, involving linguistic processing, executive functions and action organisation, reflect the location of the underlying pathology (Libon et al., 2007). SD is traditionally the language variants of FTLD and is characterised by loss of word meaning and impaired language comprehension (Gorno-Tempini et al., 2004; Hodges, Patterson, Oxbury, \& Funnell, 1992).

SD is a clinical syndrome described first by Pick (1904). In 1975, Warrington (1975) described three patients with progressive impaired recognition of objects and she hypothesised that the deficit was due to a breakdown of conceptual knowledge. Subsequently, Mesulam $(1982,1987)$ described patients with insidious disturbance of language, beginning with anomia and progressively reduced speech output and comprehension deficit, where he later

\footnotetext{
* Corresponding author. Fax: +390303501513.

E-mail address: mcotelli@fatebenefratelli.it (M. Cotelli).
}

named this syndrome primary progressive aphasia (PPA). Such patients can be distinguished based on the fluency of their speech, having either progressive nonfluent aphasia or fluent aphasia. The term 'semantic dementia' refers to fluent aphasia with additional loss of word meaning.

Later, Poeck and Luzzatti (1988) described patients with similar deficits. Only a year afterwards, Snowden, Goulding, and Neary (1989) demonstrated that these deficits were not confined to the verbal domain, and they designated these patients as suffering from a "loss of semantic information", coining the term 'semantic dementia'. These patterns of impairment were characterised as degradation of a semantic store (Warrington, 1975).

In substance, SD is characterised by loss of word meaning and impaired language comprehension, with preserved syntactic comprehension, production and fluency of speech output (Gorno-Tempini et al., 2004; Hodges et al., 1992).

SD patients' performances correlate highly between different semantic tasks and show strong item-specific consistency across modalities, suggesting that the anterior temporal lobes underpin a single store of amodal semantic knowledge (Bozeat, Lambon Ralph, Patterson, Garrard, \& Hodges, 2000; Rogers et al., 2004). Semantic memory is affected, whereas episodic memory appears intact, where this feature distinguishes SD patients from Alzheimer disease (AD) patients, at least in the first stages of the diseases (Scahill, Hodges, \& Graham, 2005).

Voxel-based morphometry studies have shown that SD is characterised by damage to the anterior temporal lobe (Gorno-Tempini et al., 2004). Temporal lobe atrophy in SD is usually bilateral, but most frequently predominant in the left hemisphere. Lateral and medial anterior regions are affected, including the perirhinal cortices and fusiform gyri (Chan et al., 2001; Galton et al., 2001; 
Gorno-Tempini et al., 2004; Mummery et al., 2000; Patterson, Nestor, \& Rogers, 2007; Rosen et al., 2002). In addition, the hypometabolism, related to the semantic memory impairment in SD patients is associated with the bilateral rostral temporal lobes, in contrast to a widespread hypometabolism in AD patients (Nestor, Fryer, \& Hodges, 2006).

In several reports of single SD cases, patients presenting a progressive prosopagnosia always showed unfamiliar face recognition, with visual basic abilities preserved, in contrast to famous face recognition impairment. As such, the prosopagnosic deficits are of associative-like type and never apperceptive in nature (Barbarotto, Capitani, Spinnler, \& Trivelli, 1995; Evans, Heggs, Antoun, \& Hodges, 1995; Gainotti, Barbier, \& Marra, 2003; Gentileschi, Sperber, \& Spinnler, 1999; Joubert et al., 2003; Sperber \& Spinnler, 2003; Tyrrell, Warrington, Frackowiak, \& Rossor, 1990). The cortical atrophy is always within the temporal lobe (bilateral, greater on the right), in its antero-inferior parts (Gainotti et al., 2003), superior temporal gyrus (Tyrrell et al., 1990) or the right fusiform gyrus (Joubert et al., 2003). Other studies have reported SD patients presenting proper naming deficit and person-specific knowledge impairment (Papagno \& Capitani, 1998; Papagno \& Capitani, 2001; Poeck \& Luzzatti, 1988; Schwarz, De Bleser, Poeck, \& Weis, 1998). The presence of these deficits in SD patients might depend on the site of the brain atrophy. Snowden et al. (2004) found that SD patients with predominant left temporal lobe atrophy were better at recognising famous faces than famous names, whereas those with right temporal predominance showed the reverse pattern. Moreover, Thompson et al. (2004) reported that specific person knowledge deficit could persist when the atrophy is predominantly on the right, whereas a general impairment knowledge is present when the temporal atrophy is predominantly on the left.

Two main theories explain these semantic deficits in SD patients. The semantic memory loss could be due to an impairment of explicit retrieval of knowledge or to a degradation of the internal representation of the semantic network (Hodges, Salmon, \& Butters, 1992; Hodges et al., 1992). At present, the most consistent hypothesis refers to a representational deficit due to a progressive semantic degradation (Jefferies, Patterson, \& Lambon Ralph, 2006; Rogers \& Friedman, 2008). In addition to the usual explicit measures of neuropsychological testing, the semantic system integrity has been investigated through implicit tasks, such as priming. The advantage of this technique is that it does not require a behavioural/overt response. In the case of repetition priming (RP), it is postulated that the processing of a stimulus (target) is facilitated when the same stimulus (prime) was encountered before. Results issuing from studies of word priming in neurodegenerative disease patients are mixed. Cumming, Graham, and Patterson (2006) found a greater facilitation effect of priming (hyperpriming) for degraded words (those not identified in an explicit recognition task) in SD patients, when compared to controls. Conversely, in Alzheimer's disease, some effects of facilitation have been found since there is a preserved semantic memory, at least at the onset of the disease (Nebes, 1989). Recently, Rogers and Friedman (2008) compared AD and SD patients using a priming task. AD patients showed a hypopriming, whereas SD patients did not show any priming effect. This has been interpreted as a relatively spared semantic network in $A D$, in contrast to a clear semantic degradation in SD.

In order to study the face and name representation in SD it would be interesting to explore the use of a priming paradigm. Typically, in this task (see for example: Burton, Kelly, \& Bruce, 1998; Johnston \& Barry, 2006), the subject is presented with a name of a famous or unknown person (prime) preceded by a related or unrelated face (target). The subject is required to make a decision (for example, a familiarity judgement task) on the target. The prime preactivates the related items, as demonstrated by the way the subject is faster to respond to the target compared to a control condition where there is no relationship between prime and target. According to this hypothesis, if a patient's explicit knowledge system is broken, but some lesser activation persists, facilitation in responses (reaction times, or RTs) could be found in RP. Conversely, if a degraded representation occurs, any kind of facilitation should be found (Shallice, 1988).

In the present study, we investigated face-name processing using an RP paradigm for faces and names in a patient with SD and in ten age-matched healthy controls. We studied the repetition effect using name-name pairs (within-domain) and face-name pairs (cross-domain). In order to investigate the semantic memory related to person representation, we decided to employ a repetition priming technique, exploiting implicit processes. This paradigm permitted us to verify if such a representation is broken or relatively spared but not accessible. The absence of a priming effect could be considered an index of a degraded representation of faces and names, instead of an impaired access to information.

Studies in healthy participants have shown that no priming effect occurred when prime and target are cross-domain (i.e., facename, name-face) (Bruce \& Valentine, 1985; Ellis, Flude, Young, \& Burton, 1996). In contrast, more recent studies have shown that priming can cross-domain inputs when the face of a famous person is immediately preceded by the same person's name (or vice versa). Calder and Young (1996) demonstrated a clear effect of cross-domain repetition priming when short intervals occurred between the prime and target of the same famous person ('self-priming'). The amount of priming was larger in within- than in crossdomain condition. Burton et al. (1998) reported evidence of cross-domain priming when the task was semantic in nature (e.g., nationality decision, dead/alive).

There is also evidence of cross-domain priming in prosopagnosic patients, in which overt face processing is impaired. De Haan, Young, and Newcombe (1992) described a prosopagnosic patient (NR) who overtly did not recognise famous faces but performed above chance in a forced-choice familiarity task. NR showed a priming effect in a cross-domain task (face-name), where this effect was restricted to those faces categorised as 'familiar' in the forced-choice task. In addition, Young, Hellawell, and De Haan (1988) described a prosopagnosic patient (PH) who could not overtly recognise familiar faces but showed facilitation of responses to targets (names or faces) preceded by semantically related primes.

We hypothesised that, in our SD patient, no effect of priming would occur in cross-domain priming; specifically, that a famous face would not facilitate the access to its own name. There could also be no effect in within-domain priming. Consequently, responses to targets (names) will not be facilitated because prime (faces and names) representation is degraded.

\section{Materials and methods}

\subsection{Subjects}

\subsection{1. $C M R$}

CMR, a 67-year-old woman with 8 years of education was diagnosed with SD according to frontotemporal dementia diagnostic criteria (McKhann et al., 2001; Neary et al., 1998). The patient underwent a structural brain MRI, and visual rating of MRI images was compatible with the clinical diagnosis. MRI scanning (July 2007) revealed left temporal lobe atrophy, with consequent enlargement of ventricles, associated with signal abnormalities within the right inferior parietal cortex (see Fig. 1). The patient had no clinical signs of motor or sensory deficits.

Extensive neuropsychological assessment was performed, including global functioning, leaning and memory, non-verbal rea- 

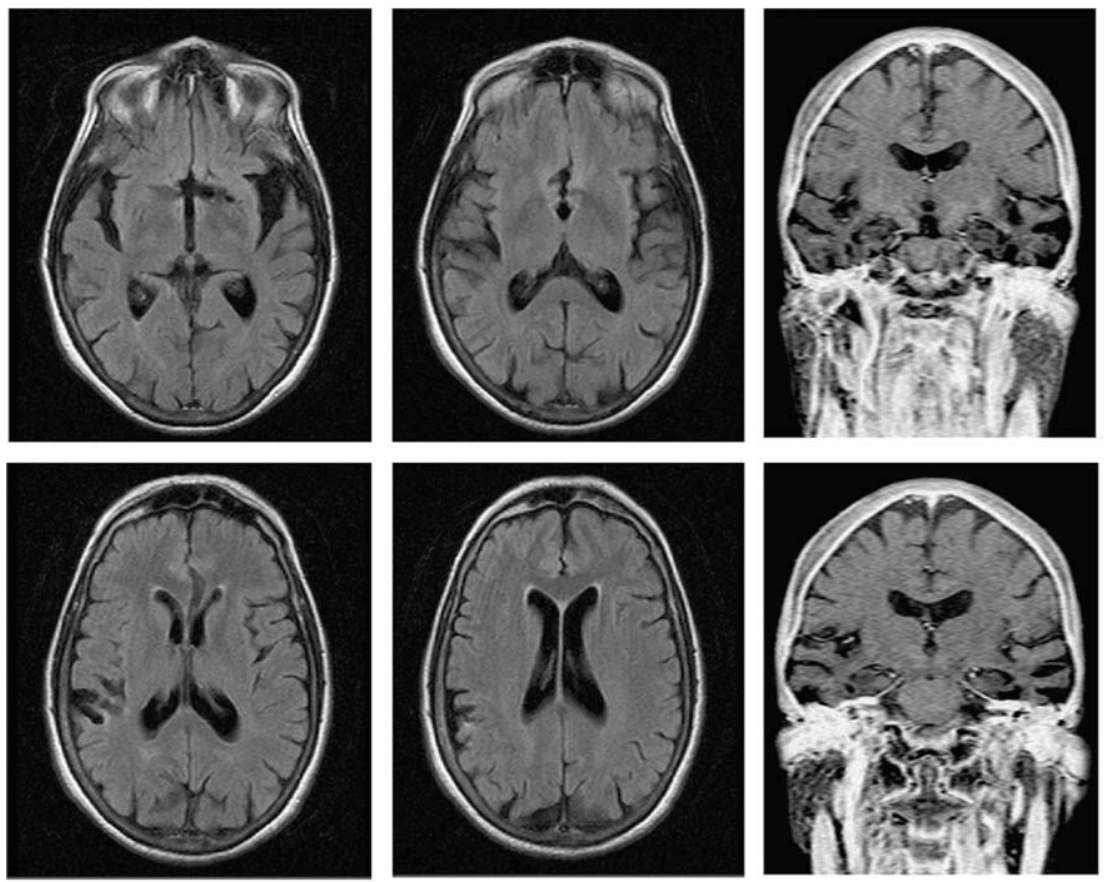

Fig. 1. CMR'S MRI scan: a coronal and a horizontal section showing temporal atrophy, greater on the left.

soning, language, visuospatial and visuoperception abilities, attentional, executive and praxis functioning.

The Mini-Mental State Examination revealed a score of 26/30 (Folstein, Folstein, \& McHugh, 1975), retrieving three out of three items on delayed recall. Detailed neuropsychological testing showed memory and language impairment as well as difficulties in recognition of famous faces, whereas visuospatial, perceptual and praxis abilities were spared. Results from the baseline cognitive assessment are reported in Table 1.

Language functions, such as repetition, naming, reading, writing and comprehension, were formally assessed with the full Italian version of the Aachener Aphasie Test (AAT) (Luzzatti et al., 1994). Picture naming was assessed with an action and object naming task of battery for aphasia, such as BADA ('Batteria per l'Analisi Dei Deficit Afasici'; Miceli, Laudanna, Burani, \& Capasso, 1994). Formal speech evaluation demonstrated normal motor speech, reading and writing skills, but a marked deficit in word retrieval and sentence comprehension. Auditory verbal comprehension in a conversation setting was good; on testing, it was preserved for simple commands (see token test section of the AAT).

CMR's spontaneous speech was fluent, with normal articulation without jargon output or echolalia. Repetition, reading and writing were spared. Picture naming was severely impaired. The patient produced the correct response to $6 / 30$ objects (20\%) and to $12 / 28$ actions (43\%) in oral naming. Incorrect responses resulted in semantically related responses, semantic circumlocutions or anomia.

Non-verbal cognitive tests did not disclose buccofacial, ideomotor and constructive apraxia.

A detailed assessment of visuoperceptual abilities was performed (see Table 1, panel C). CMR showed normal performance on basic visuoperceptual abilities assessed with The Visual Object and Space Perception VOSP (James \& Warrington, 1991). The patient performed poorly only on silhouettes and object recognition subtests. It is important to note that the pathological scores in these two latter subtests could be biased by the language deficits.

On a facial recognition test (Benton, Sivan, Hamsher, Varney, \& Spreen, 1990) that required the ability to match unfamiliar faces,
CMR obtained a borderline score (correct responses 39 out of 54, cut-off score 38).

On a gender judgement task, the patient performance was unimpaired (100\% correct responses). In this task, a set of 64 pictures portraying unfamiliar male and female faces was used. Half the faces depicted all the facial features, while the other half lacked external features (no hair). Stimuli were presented on the monitor of a PC and they remained on the screen until a response was made. CMR performed perfectly in this task $(100 \%$ correct responses).

On recognition of famous faces (Rizzo, Venneri, \& Papagno, 2002), the patient failed at the retrieval of semantic knowledge and the naming of famous people on picture presentation. In this test, half famous and half unfamiliar faces were presented, where the patient was required to recognise famous faces, provide semantic knowledge and name them. In the fame judgement subtest, CMR correctly recognised 18 out of 50 famous faces.

Finally, on recognition of famous names (Bizzozero, Lucchelli, Pozzoli, Saetti, \& Spinnler, 2007), a task that required the patient to recognise famous names printed on a sheet, presented in a series half famous and half unfamiliar names, CMR performed below cutoff.

To summarise, CMR showed a fluent progressive aphasia with naming and comprehension difficulties, as well as loss of verbal and non-verbal semantic knowledge about objects, concepts, people and meaning of words, and recognition of famous faces.

\subsubsection{Healthy participants}

Two different groups of ten healthy control subjects were recruited for each experiment. None of the controls had a history of neurological or psychiatric disease, head injury or alcohol abuse, neither were they under treatment for major illness. Controls were tested using Mini-Mental State Examination Test, Trial Making Test for executive functions, memory for Prose and Wechsler Memory Scale for memory abilities (Lezak, Howieson, \& Loring, 2004). All the controls performed within normal range for all the neuropsychological tests.

A pilot study with young participants showed that the percentage of priming effect was of $9.7( \pm 3.9)$ compared to neutral condi- 
tions. Therefore, the sample size of controls is sufficient according to the study design required from the pilot study results (considering an $80 \%$ of power and a .05 level test of significance on the expected mean difference).

In Experiment 1, the mean age of healthy participants was 67.5 $( \pm 5.7)$ and the mean years of education was $10.0( \pm 2.9)$. In Experiment 2 , the mean age of healthy participants was $71.4( \pm 5.7)$ and the mean years of education was $11.2( \pm 3.4)$. The controls did

Table 1

Neuropsychological assessment. Asterisk for raw scores indicate that the patient's performance is below cut-off.

\begin{tabular}{|c|c|c|c|c|}
\hline \multirow[b]{2}{*}{ (A) } & \multirow[t]{2}{*}{$\begin{array}{l}\text { Raw } \\
\text { scores }\end{array}$} & \multicolumn{2}{|c|}{$\begin{array}{l}\text { Adjusted } \\
\text { scores }\end{array}$} & \multirow[t]{2}{*}{ Cut-off } \\
\hline & & & & \\
\hline $\begin{array}{l}\text { Mini-Mental State Examination } \\
\text { Non-verbal reasoning }\end{array}$ & $26 / 30$ & \multicolumn{2}{|l|}{24} & 24 \\
\hline Raven colored progressive matrices & $21 / 36$ & \multicolumn{2}{|c|}{23.5} & 18 \\
\hline $\begin{array}{l}\text { Long-term memory } \\
\text { Rey auditory-verbal learning test- } \\
\text { immediate recall }\end{array}$ & $13 / 75^{*}$ & \multicolumn{2}{|l|}{17} & 28.52 \\
\hline $\begin{array}{l}\text { Rey auditory-verbal learning test-delayed } \\
\text { recall }\end{array}$ & $4 / 15$ & \multicolumn{2}{|l|}{5.3} & 4.68 \\
\hline Rey-osterrieth complex figure-recall & \multicolumn{3}{|l|}{$0 / 36^{*}$} & 9.47 \\
\hline \multicolumn{5}{|l|}{ Short-term memory } \\
\hline Digit span & \multicolumn{3}{|c|}{4.25} & 3.75 \\
\hline Spatial span & \multicolumn{3}{|c|}{5,25} & 3.75 \\
\hline \multicolumn{5}{|l|}{ Language } \\
\hline Controlled association letters test & $1_{*}^{*}$ & \multicolumn{2}{|l|}{5} & 17 \\
\hline Controlled association categories test & 3 & \multicolumn{2}{|l|}{7} & 25 \\
\hline \multicolumn{5}{|l|}{ Praxis } \\
\hline Buccofacial apraxia & $19 / 20$ & \multicolumn{2}{|l|}{19} & 18 \\
\hline Ideomotor apraxia - right upper limb & \multicolumn{3}{|l|}{$67 / 72$} & 62 \\
\hline Ideomotor apraxia - left upper limb & \multicolumn{3}{|l|}{$69 / 72$} & 62 \\
\hline Rey figure - copy & \multicolumn{3}{|l|}{$31 / 36$} & 28.88 \\
\hline \multicolumn{5}{|l|}{ Attentional and executive functions } \\
\hline Trial making test $\mathrm{A}$ & 56 & \multicolumn{2}{|l|}{36} & 93 \\
\hline Trial making test $\mathrm{B}$ & 321 & \multicolumn{2}{|c|}{253} & 282 \\
\hline $\begin{array}{l}\text { Aphasic battery for analysis of aphasic } \\
\text { deficits(bada) }\end{array}$ & \multicolumn{3}{|c|}{ Raw scores } & Cut-off \\
\hline (B) & & & & \\
\hline Oral object naming & & & & 28 \\
\hline Oral action naming & & & & 26 \\
\hline Aachener Aphasie Test (AAT) & & & Tscore & Cut-off \\
\hline Token test & & & 56 & $<7$ \\
\hline Ripetition & & 150 & 65 & 142 \\
\hline Writing & & & 71 & 81 \\
\hline Naming & & & 52 & 104 \\
\hline Comprehension & & & 45 & 108 \\
\hline Visuoperceptual abilities & Rav & ores & & Cut-off \\
\hline
\end{tabular}

(C)

The visual object and space perception battery (VOSP)

Incomplete letters

Silhouettes

$17 / 20$

Object recognition

Progressive silhouettes

Dot counting

Position discrimination

Number location

Cube analysis

Facial recognition test

Recognition of famous faces

Fame judgement on picture presentation

Semantic knowledge of famous people

Naming of famous people on picture

presentation.

Recognition of famous names

$\begin{array}{lll}17 / 20 & & 15 \\ 7 / 30^{*} & & 16 \\ 13 / 20^{*} & & 17 \\ 14 / 20 & & <15 \\ 10 / 20 & & 8 \\ 19 / 20 & & 18 \\ 10 / 10 & & 7 \\ 8 / 10 & & 6 \\ 39 / 54 & & 38 \\ & & \\ 4 / 50 & 4 & 12.90 \\ 7.75 / 50^{*} & 12.5 & 22.17 \\ 0 / 50 & 0 & 1450 \\ & & \\ 2193.5^{*} & 2257.96 & 6666.46\end{array}$

not differ significantly from the patient's ages or education $(p>.05)$.

\subsection{Experimental tasks}

\subsubsection{Experiment 1: cross-domain priming for faces and names}

2.2.1.1. Stimuli and procedure. Stimuli included grey-scale faces and proper names. Faces were downloaded from electronic free datasets and other resources on the web, and processed by Adobe Photoshop 5.0. Images were scaled to $210 \times 263$ pixels and presented from a distance of $100 \mathrm{~cm}$ (subtending a visual angle of $\sim 3.15^{\circ} \times 4^{\circ}$ ). The photographs portraying famous faces were of well-known politicians, movie stars and other famous celebrities. We conducted a pilot study to define the set of pictures to be used in the experiment. We considered only pictures with a percentage of correct responses above $90 \%$.

Subjects were presented with a face for $500 \mathrm{~ms}$ (prime), followed by a proper name (target). Subjects were required to read aloud the names presented, and these remained on the screen until the response was made. Vocal reaction times were recorded via a microphone.

The experiment consisted of three blocks of 24 face-name pairs each, and a practise session. Three prime types were given to famous face targets, such as:

1. Same person prime: a famous face as a prime followed by the corresponding proper name as a target.

2. Unrelated famous prime: a famous face as a prime followed by an unrelated famous proper name as a target.

3. Unfamiliar prime: an unfamiliar face as a prime followed by a famous proper name as a target.

Only one prime type (unfamiliar face) was given to unfamiliar proper name targets.

In healthy participants, fame judgement for primes was performed offline when all the experiments were run. Stimuli that were not recognised as famous were excluded from calculation.

\subsubsection{Experiment 2: within-domain priming for names}

2.2.2.1. Stimuli and procedure. Subjects were presented with a proper name for $500 \mathrm{~ms}$ (prime), followed by a mask for $300 \mathrm{~ms}$ and a second proper name (target). Subjects were required to read aloud the names presented, and they remained on the screen until the response was made. Stimuli were presented in the centre of the screen, in 24 point Arial font, over two lines (one line for the forename, and a second line for the surname, in capital letters). Targets were presented in bold. Vocal reaction times were recorded via a microphone.

The experiment consisted of three blocks of 20 face-name pairs each, as well as a practice session. We considered the same prime type as in the cross-domain priming experiment. In the case of selfpriming, the two proper names were the same.

\section{Statistical analysis}

Reaction times (RTs) exceeding two standard deviations above and below the means were excluded from analysis. Statistical analyses were performed first on reaction times, considering all the priming conditions. Then, we performed analyses on difference RTs calculated as follows: (a) same person prime condition minus unfamiliar prime-target condition and (b) unrelated famous prime condition minus unfamiliar prime-target condition.

Only the 'unfamiliar prime-target condition' was used as a control condition because there was no statistical difference from the unfamiliar prime-famous target condition for the cross-domain 
Table 2

Vocal RTs (in milliseconds) in the within- and cross-domain priming experiment. Values are reported as means and standard deviations in brackets.

\begin{tabular}{|c|c|c|c|c|}
\hline \multirow[t]{2}{*}{ Prime } & \multicolumn{3}{|c|}{ Familiar target } & \multirow[t]{2}{*}{ Unfamiliar target } \\
\hline & Same & Unrelated & Unfamiliar & \\
\hline \multicolumn{5}{|c|}{ Cross-domain } \\
\hline CMR & 658 & 648 & 657 & 655 \\
\hline Controls & $676(83)$ & $731(75)$ & 729 (74) & 727 (77) \\
\hline \multicolumn{5}{|c|}{ Within-domain } \\
\hline CMR & 677 & 687 & 682 & 691 \\
\hline Controls & $686(94)$ & 742 (89) & $729(83)$ & 747 (100) \\
\hline
\end{tabular}

$(t(9)=.50, p=.63)$, and for the within-domain $(t(9)=.47, p=.64)$. RTs for each condition are reported in Table 2.

The effect of priming in control participants was tested using a $t$-test for one sample, considering an expected mean of zero (null hypothesis of no priming effect). Additionally, $t$-tests for independent samples were used to compare CMR and controls' performances. We used a modified $t$-test described by Crawford and Howell (1998), because it is more appropriate when the individual as a sample is one and the control group is small. The level of significance was set at .05 .

\section{Results}

\subsection{Experiment 1: cross-domain repetition priming}

Analyses performed on the priming effect revealed that, in healthy participants, the RT difference between the same person and the unfamiliar prime-target condition was significantly different from zero (Mean $=51 \mathrm{~ms} ; \mathrm{SD}=20.1 ; t(9)=7.53, p<.0001$ ). CMR's priming effect $(-3 \mathrm{~ms})$ was statistically different from controls in this condition $(t(9)=-2.53, p=.02)$.

For healthy participants, there was no priming effect for RT difference between the unrelated famous and the unfamiliar primetarget condition (Mean $=-4 \mathrm{~ms}, \mathrm{SD}=25.0, t(9)=-.46, p=.65$ ). No difference was found between CMR's priming effect $(7 \mathrm{~ms})$ and that of controls in this condition $(t(9)=.41, p=.35$ ) (see Fig. 2, panel A).

After the experimental task, CMR was asked to perform a forced-choice familiarity judgement of faces previously seen. In this task, her score was of $36 \%$ of correct responses. In particular, her performance was characterised by a high rate of misses $(52 \%$, she did not recognise famous faces as famous) and by false alarms (75\%, she categorised unfamiliar faces as famous).

\subsection{Experiment 2: within-domain repetition priming}

Analyses performed on the priming effect revealed that the CMR's RT difference (14 ms) between the same person and the unfamiliar prime-target condition was not statistically different from that of controls $(t(9)=-1.54, p=.08)$. In healthy participants, this difference was significantly different from zero $($ Mean $=61 \mathrm{~ms} ; \mathrm{SD}=27.7 ; t(9)=6.61, p<.0001$ ).

Moreover, there was no priming effect for RT difference between the unrelated famous and the unfamiliar prime-target condition in healthy participants (Mean $=5.0 \mathrm{~ms}, \mathrm{SD}=19.0, t(9)=.48$, $p=.64)$. No difference was found between CMR's priming effect $(4 \mathrm{~ms})$ and that of controls in this condition $(t(9)=.04, p=.48)$ (see Fig. 2, panel B).

The effects of priming in Experiment 1 (cross-domain) and Experiment 2 (within-domain) did not differ statistically in healthy participants $(t(18)=.92, p<.37)$.
A

CROSS DOMAIN PRIMING

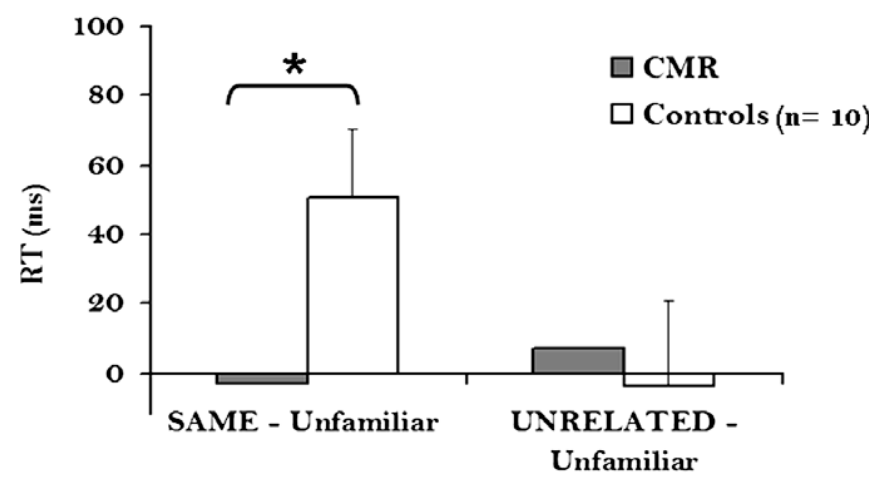

B WITHIN DOMAIN PRIMING

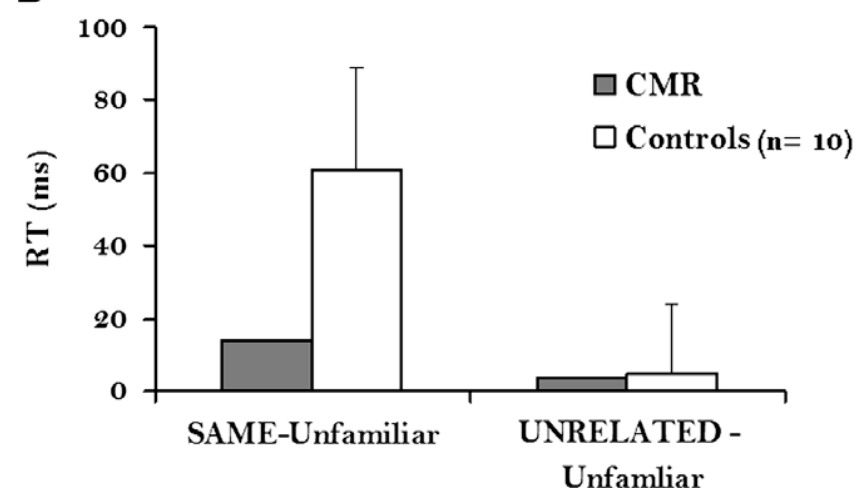

Fig. 2. (A) Cross-domain priming effect. Effect of priming calculated as a difference of conditions: same person prime and target, unrelated famous prime and famous name minus unfamiliar face prime and target. (B) Within-domain priming effect. Effect of priming calculated as a difference of conditions: same person prime and target, unrelated famous name and famous name, minus unfamiliar name prime and target. Values are means with standard deviations as bars.

\section{Discussion}

We investigated implicit and explicit processing of famous faces and names in an SD patient (CMR) who presented a prominent proper anomia and person-specific knowledge impairment. The association of these two deficits allowed us to define the proper naming impairment as semantic in nature, and not only at a post-semantic or retrieval level (Semenza, 2006). Famous face recognition was poor; the patient performed below chance (36\%) in the fame judgement test. Conversely, her abilities to process configurational aspects of faces were preserved. CMR was relatively good in matching unfamiliar faces and excellent in gender judgement. Taken together, we can claim that her impairment of face processing was of an 'associative' type, as those reported in the previous studies in literature (e.g., Snowden et al., 2004). These measures permitted the investigation of the explicit processes of conceptual knowledge of famous faces and proper names.

We further investigated the implicit processing of semantic memory. In order to clarify the nature of this deficit, we used a paradigm of within- and cross-domain priming of faces and names. No effect of repetition priming in CMR was found, where this could permit the exclusion of a possible deficit of access of proper names. To collect an adequate amount of analysable data, a reading task was used instead of a behavioural response, such as familiarity judgement. In a famous face recognition test, CMR performed below chance and this means that a large amount of data could have been missed if we had used an explicit response. Other tasks, such as gender or facial expression judgement, were not ideal because 
they are known not to produce any kind of priming effect (Ellis, Young, \& Flude, 1990). The presence of a clear effect of priming in healthy controls supports our hypothesis that priming occurred in some way, even if the task was not semantic in nature. Moreover, other studies have used a similar task, such as threshold oral reading, in lexical priming task in $\mathrm{AD}$ patients (Glosser \& Friedman, 1991; Glosser, Friedman, Grugan, Lee, \& Grossman, 1998). These authors found significant effect of priming in associated and semantically related words in AD patients.

The main outcome of this study is that our SD patient did not show any kind of priming effect, since previous presentation of an item directly related to the target did not facilitate the processing of the target. This effect was clear when the target (name) was preceded by a face (cross-domain condition) while, in the withindomain condition (a name primed by a name), a small priming effect was found in CMR. This is probably due to a visual similarity of repeated letters.

These effects could be explained according to cognitive models of face processing and naming. In particular, the Interactive Activation and Competition (IAC) model developed by Burton, Bruce, and Johnston (1990), the connectionist model based on the Bruce and Young's (1986) model, makes some predictions in that sense. The IAC implementation postulates four types of units: one for faces (FRUs), one for names (NIUs, Name Input Units), one for classification of the person (PINs) and the last one for semantic information (SIUs, Semantic Information Units). Burton et al. (1990) proposed that the recognition of a familiar name is speeded up when it is preceded by the same person's face only for semantic priming but not for repetition, because this latter is domain specific. However, conversely, we found the effect also when cross-domain selfpriming occurred. As Burton et al. (1990) pointed out, repetition priming is short-lasting and, in our experiment, we found the effect because prime and target occurred immediately. The locus of this priming could be explained by the claim made by Burton et al. (1990). They postulated that a familiarity decision is made at the PIN level, because these are units allowing the access to semantic information. Therefore, for these authors, priming occurs at this level. CMR showed semantic and person identity knowledge deficits, where this precludes the target from benefiting from a previous exposure to the prime of the same individual. The non-preactivation of the prime, due to a degraded representation in CMR, does not enhance the threshold at the PIN level. Consequently, the target recognition was not facilitated.

The null effect for unrelated pairs needs some explanation. According to the IAC model, only a closed, semantically related item could benefit from facilitation of recognition. Moreover, it is possible that some kind of inhibition could exist, and that the balance between excitatory and inhibitory effects contributes to the total effect. As such, it could be that the two strengths of connection cancel each other out, resulting in a null effect (Calder \& Young, 1996). Other studies in young people (Jemel, Pisani, Rousselle, Crommelinck, \& Bruyer, 2005) and in adults (Schweinberger, $1995)$ have reported the same pattern of results in this regard.

Previous studies (Calder \& Young, 1996; Johnston \& Barry, 2006) found that, in within-domain repetition, priming is greater than in cross-domain conditions. This is because different factors contribute to such a larger facilitation, in particular the increased activation in the appropriate PIN, and the strengthened NIU-PIN connection for names, and FRU-PIN connection for faces. These processes both occur in the same domain, without a cost when switching to a different domain, even if we do not find the same advantage for the within-domain condition.

In summary, we found that explicit and implicit measures of famous face processing and proper naming demonstrated a semantic deficit in our SD patient. The consistency of the results for these two measures could account for a semantic loss of representation, as previously found for language studies in SD (Nakamura, Nakanishi, Hamanaka, Nakaaki, \& Yoshida, 2000; Rogers \& Friedman, 2008; Tyler \& Moss, 1998). Further investigations in a group of SD patients are needed to explore this hypothesis of degraded knowledge for famous faces and proper names.

\section{References}

Barbarotto, R., Capitani, E., Spinnler, H., \& Trivelli, C. (1995). Slowly progressive semantic impairment with category specificity. Neurocase, 1, 107-119.

Bauer, R. M. (2003). Agnosia. In K. Heilman \& E. Valenstein (Eds.), Clinical neuropscyhology (4th ed., pp. 236-295). New York: Oxford University Press.

Benton, A. L., Sivan, A. B., Hamsher, K. de S., Varney, N. R., \& Spreen, O. (1990). Test di Riconoscimento di volti (facial recognition). Firenze, Italy: Organizzazioni Speciali.

Bizzozero, I., Lucchelli, F., Pozzoli, S., Saetti, M. C., \& Spinnler, H. (2007). What do you know about Ho Chi Minh? Italian norms of proper name comprehension. Neurological Science, 28(1), 16-30.

Bozeat, S., Lambon Ralph, M. A., Patterson, K., Garrard, P., \& Hodges, J. R. (2000) Non-verbal semantic impairment in semantic dementia. Neuropsychologia, 38(9), 1207-1215.

Bruce, V., \& Valentine, T. (1985). Identity priming in the recognition of familiar faces. British Journal of Psychology, 76(Pt 3), 373-383.

Bruce, V., \& Young, A. (1986). Understanding face recognition. British Journal of Psychology, 77(Pt 3), 305-327.

Burton, A. M., Bruce, V., \& Johnston, R. A. (1990). Understanding face recognition with an interactive activation model. British Journal of Psychology, 81(Pt 3), 361-380.

Burton, A. M., Kelly, S. W., \& Bruce, V. (1998). Cross-domain repetition priming in person recognition. Quarterly Journal of Experimental Psychology, 51A, 515-529.

Calder, A. J., \& Young, A. W. (1996). Self priming: A short-term benefit of repetition. Quarterly Journal of Experimental Psychology, 49A, 845-861.

Chan, D., Fox, N. C., Scahill, R. I., Crum, W. R., Whitwell, J. L., Leschziner, G., et al (2001). Patterns of temporal lobe atrophy in semantic dementia and Alzheimer's disease. Annals of Neurology, 49(4), 433-442.

Crawford, J. R., \& Howell, D. C. (1998). Comparing an individual's test score against norms derived from small sample. The Clinical Neuropsychologist, 12(4), 482-486.

Cumming, T. B., Graham, K. S., \& Patterson, K. (2006). Repetition priming and hyperpriming in semantic dementia. Brain and Language, 98(2), 221-234.

De Haan, E. H. (2000). Face perception and recognition. In B. Rapp (Ed.), The handbook of cognitive neuropsychology (pp. 75-100). Philadelphia: Psychology Press.

De Haan, E. H., Young, A. W., \& Newcombe, F. (1992). Neuropsychological impairment of face recognition units. Quarterly Journal of Experimental Psychology A, Human Experimental Psychology, 44(1), 141-175.

Ellis, A. W., Young, A. W., \& Flude, B. M. (1990). Repetition priming and face processing: Priming occurs within the system that responds to the identity of a face. Quarterly Journal of Experimental Psychology. A, Human Experimental Psychology, 42(3), 495-512.

Ellis, A. W. Flude, B. M., Young A. \& Burton, A. M. (1996). Two loci of repetition priming in the recognition of familiar faces. Journal of Experimental Psychology: Learning, Memory and Cognition, 22(2), 295-308.

Evans, J. J., Heggs, A. J., Antoun, N., \& Hodges, J. R. (1995). Progressive prosopagnosia associated with selective right temporal lobe atrophy. A new syndrome? Brain 118(Pt 1), 1-13.

Folstein, M. F., Folstein, S. E., \& McHugh, P. R. (1975). Mini-mental state. A practica method for grading the cognitive state of patients for the clinician. Journal of Psychiatry Research, 12(3), 189-198.

Gainotti, G., Barbier, A., \& Marra, C. (2003). Slowly progressive defect in recognition of familiar people in a patient with right anterior temporal atrophy. Brain, 126(Pt 4), 792-803.

Galton, C. J., Patterson, K., Graham, K., Lambon Ralph, M. A., Williams, G., Antoun, N., et al. (2001). Differing patterns of temporal atrophy in Alzheimer's disease and semantic dementia. Neurology, 57(2), 216-225.

Gentileschi, V., Sperber, S., \& Spinnler, H. (1999). Progressive defective recognition of familiar people. Neurocase, 5(5), 407-424.

Glosser, G., \& Friedman, R. B. (1991). Lexical but not semantic priming in Alzheimer's disease. Psychology and Aging, 6(4), 522-527.

Glosser, G., Friedman, R. B., Grugan, P. K., Lee, J. H., \& Grossman, M. (1998). Lexica semantic and associative priming in Alzheimer's disease. Neuropsychology, $12(2), 218-224$

Gorno-Tempini, M. L., Dronkers, N. F., Rankin, K. P., Ogar, J. M., Phengrasamy, L. Rosen, H. J., et al. (2004). Cognition and anatomy in three variants of primary progressive aphasia. Annals of Neurology, 55(3), 335-346.

Hodges, J. R., Patterson, K., Oxbury, S., \& Funnell, E. (1992). Semantic dementia. Progressive fluent aphasia with temporal lobe atrophy. Brain, 115(Pt 6), 1783-1806.

Hodges, J. R., Salmon, D. P. \& Butters, N. (1992). Semantic memory impairment in Alzheimer's disease: Failure of access or degraded knowledge? Neuropsychologia, 30(4), 301-314.

James, M., \& Warrington, E. K. (1991). The visual object and space perception battery. Suffolk, UK: Thames Valley Test Company.

Jefferies, E., Patterson, K., \& Lambon Ralph, M. A. (2006). The natural history of latestage "pure" semantic dementia. Neurocase, 12(1), 1-14. 
Jemel, B., Pisani, M., Rousselle, L., Crommelinck, M., \& Bruyer, R. (2005). Exploring the functional architecture of person recognition system with event-related potentials in a within - and cross-domain self-priming of faces. Neuropsychologia, 43(14), 2024-2040.

Johnston, R. A., \& Barry, C. (2006). Repetition priming of access to biographical information from faces. Quarterly Journal of Experimental Psychology, 59(2), 326-339.

Joubert, S., Felician, O., Barbeau, E., Sontheimer, A., Barton, J. J., Ceccaldi, M., et al. (2003). Impaired configurational processing in a case of progressive prosopagnosia associated with predominant right temporal lobe atrophy. Brain, 126(Pt 11), 2537-2550.

Lezak, M., Howieson, D., \& Loring, D. W. (2004). Neuropsychological assessment (4th ed.). Oxford: University Press.

Libon, D. J., Xie, S. X., Moore, P., Farmer, J., Antani, S., McCawley, G., et al. (2007). Patterns of neuropsychological impairment in frontotemporal dementia. Neurology, 68(5), 369-375.

Luzzatti, C., Willmes, K., De Bleser, R., Bianchi, A., Chiesa, G., De Tanti, A., et al. (1994). Nuovi dati normativi per la versione italiana dell'Aachener Aphasia test. Archivio di Psicologia, Neurologia e Psichiatria, 55, 1086-1131.

McKhann, G. M., Albert, M. S., Grossman, M., Miller, B., Dickson, D., \& Trojanowski, J. Q. (2001). Clinical and pathological diagnosis of frontotemporal dementia: Report of the work group on frontotemporal dementia and Pick's disease. Archives of Neurology, 58(11), 1803-1809.

Mesulam, M. M. (1982). Slowly progressive aphasia without generalized dementia. Annals of Neurology, 11(6), 592-598.

Mesulam, M. M. (1987). Primary progressive aphasia - differentiation from Alzheimer's disease slowly progressive aphasia without generalized dementia. Annals of Neurology, 22(4), 533-534.

Miceli, G., Laudanna, A., Burani, C., \& Capasso, R. (1994). Batteria per l'analisi deideficit afasici: B.A.D.A. Milano: CEPSAG - Univeristà Cattolica del Sacro Cuore.

Mummery, C. J., Patterson, K., Price, C. J., Ashburner, J., Frackowiak, R. S., \& Hodges, J. R. (2000). A voxel-based morphometry study of semantic dementia: Relationship between temporal lobe atrophy and semantic memory. Annals of Neurology, 47(1), 36-45.

Nakamura, H., Nakanishi, M., Hamanaka, T., Nakaaki, S., \& Yoshida, S. (2000). Semantic priming in patients with Alzheimer and semantic dementia. Cortex, 36(2), 151-162.

Neary, D., Snowden, J. S., Gustafson, L., Passant, U., Stuss, D., Black, S., et al. (1998). Frontotemporal lobar degeneration: A consensus on clinical diagnostic criteria. Neurology, 51(6), 1546-1554.

Nebes, R. D. (1989). Semantic memory in Alzheimer's disease. Psychological Bulletin, 106(3), 377-394

Nestor, P. J., Fryer, T. D., \& Hodges, J. R. (2006). Declarative memory impairments in Alzheimer's disease and semantic dementia. Neuroimage, 30(3), 1010-1020.

Papagno, C., \& Capitani, E. (1998). Proper name anomia: A case with sparing of the first-letter knowledge. Neuropsychologia, 36(7), 669-679.

Papagno, C., \& Capitani, E. (2001). Slowly progressive aphasia: A four-year follow-up study. Neuropsychologia, 39(7), 678-686.

Patterson, K., Nestor, P. J., \& Rogers, T. T. (2007). Where do you know what you know? The representation of semantic knowledge in the human brain. Nature Reviews Neuroscience, 8(12), 976-987.

Pick, A. (1904). Zur symptomatologie der linksseitigen schläfenlappenatrophie. Monatsschrift für Psychiatrie und Neurologie, 16, 378-388.
Poeck, K., \& Luzzatti, C. (1988). Slowly progressive aphasia in three patients. The problem of accompanying neuropsychological deficit. Brain 111(Pt 1), 151-168.

Rizzo, S., Venneri, A., \& Papagno, C. (2002). Famous face recognition and naming test: A normative study. Neurological Science, 23(4), 153-159.

Rogers, S. L., \& Friedman, R. B. (2008). The underlying mechanisms of semantic memory loss in Alzheimer's disease and semantic dementia. Neuropsychologia, 46(1), 12-21.

Rogers, T. T., Lambon Ralph, M. A., Garrard, P., Bozeat, S., McClelland, J. L., Hodges, J. R., et al. (2004). Structure and deterioration of semantic memory: A neuropsychological and computational investigation. Psychology Review, 111(1), 205-235.

Rosen, H. J., Gorno-Tempini, M. L., Goldman, W. P., Perry, R. J., Schuff, N., Weiner, M., et al. (2002). Patterns of brain atrophy in frontotemporal dementia and semantic dementia. Neurology, 58(2), 198-208.

Scahill, V. L., Hodges, J. R., \& Graham, K. S. (2005). Can episodic memory tasks differentiate semantic dementia from Alzheimer's disease? Neurocase, 11(6), 441-451.

Schwarz, M., De Bleser, R., Poeck, K., \& Weis, J. (1998). A case of primary progressive aphasia. A 14-year follow-up study with neuropathological findings. Brain, 121(Pt 1), 115-126.

Schweinberger, S. R. (1995). Personal name recognition and associative priming in patients with unilateral brain damage. Brain and Cognition, 29(1), 23-35.

Semenza, C. (2006). Retrieval pathways for common and proper names. Cortex, 42(6), 884-891.

Semenza, C., Mondini, S., Borgo, F., Pasini, M., \& Sgaramella, M. T. (2003). Proper names in patients with early Alzheimer's disease. Neurocase, 9(1), 63-69.

Semenza, C., Mondini, S., \& Zettini, M. (1995). The anatomical basis of proper name processing: A critical review. Neurocase, 1, 183-188.

Shallice, T. (1988). From neuropsychology to mental structure. Cambridge: Cambridge University Press.

Snowden, J. S., Goulding, P. J., \& Neary, D. (1989). Semantic dementia: A form of circumscribed cerebral atrophy. Behavioural Neurology, 2, 167-182.

Snowden, J. S., Thompson, J. C., \& Neary, D. (2004). Knowledge of famous faces and names in semantic dementia. Brain, 127(Pt 4), 860-872.

Sperber, S., \& Spinnler, H. (2003). Covert person recognition: Its fadeout in a case of temporal lobe degeneration. Cortex, 39(1), 57-67.

Thompson, S. A., Graham, K. S., Williams, G., Patterson, K., Kapur, N., \& Hodges, J. R. (2004). Dissociating person-specific from general semantic knowledge: Roles of the left and right temporal lobes. Neuropsychologia, 42(3), 359-370.

Tyler, L. K., \& Moss, H. E. (1998). Going, going, gone? Implicit and explicit test of conceptual knowledge in a longitudinal study of semantic dementia. Neuropsychologia, 36(12), 1313-1323.

Tyrrell, P. J., Warrington, E. K., Frackowiak, R. S., \& Rossor, M. N. (1990). Progressive degeneration of the right temporal lobe studied with positron emission tomography. Journal of Neurology, Neurosurgery and Psychiatry, 53(12), 1046-1050.

Warrington, E. K. (1975). The selective impairment of semantic memory. Quarterly Journal of Experimental Psychology, 27(4), 635-657.

Werheid, K., \& Clare, L. (2007). Are faces special in Alzheimer's disease? Cognitive conceptualisation, neural correlates, and diagnostic relevance of impaired memory for faces and names. Cortex, 43(7), 898-906.

Young, A. W., Hellawell, D., \& De Haan, E. H. (1988). Cross-domain semantic priming in normal subjects and a prosopagnosic patient. Quarterly Journal of Experimental Psychology A, Human Experimental Psychology, 40(3), 561-580. 